LEACHING OF AMYLOSE FROM WHEAT AND CORN STARCH

by

YONGCHENG SHI

,

B.S., Zhejiang University, China, 1984

\title{
A THESIS
}

Submitted in partial fulfillment of the requirements for the degree

MASTER OF SCIENCE

Department of Grain Science and Industry

KANSAS STATE UNIVERSITY

Manhattan, Kansas

1989

Approved by:

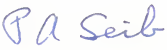

Major Professor 
TABLE OF CONTENTS

Page

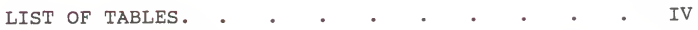

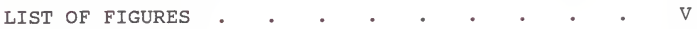

ACKNOWLEDGEMENTS . . . . . . . . . . VII

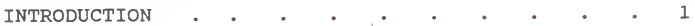

MATERIALS AND METHODS • • . • . . . . 5

Materials . . . . . . . . . 5

General Methods . . . . . . . 6

Extraction of Lipids from Starch • . * . 7

Amylose Determination and Isolation

of Its n-Butanol Complex . . . . 7

Annealing of Starch Granules . . . . 8

Cross-linking of Starch . . . . . 8

Swelling Power and Solubility of Starch . . 9

Clarity of supernatant . . . . . 10

Lipid in Amylose Leached from

Wheat Starch $\quad . \quad+\quad . \quad \cdot \quad \cdot 11$

Size-Exclusion Chromatography of the Gel

Phase after Leaching Wheat Starch . . . 11 RESULTS AND DISCUSSIONS • • • • • • • $\quad$ • 13

Effect of Temperature and Lipids of

Swelling and Solubility of Native Starch . . 13

Phase Diagram . . . . . . . . 16

Starch Level in Slurry; Effect on Yield 
Page

of Solubles During Leaching . . . 20

Effect of Annealing, Heating Rate,

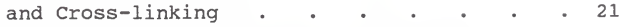

AM Obtained by Leaching Compared to AM

Isolated by Crystallizing Its

n-Butanol complex . . . . . . . 23

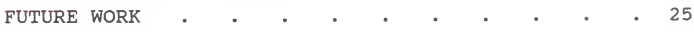

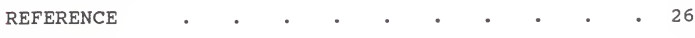




\section{LIST OF TABLES}

Table

Page

1. Some Characteristics of Wheat and Corn Starch $\quad . \quad$ • $\quad . \quad \cdot \quad \cdot 33$

2. Clarity of Supernatant after Leaching Starch (1.5\%) at Different Temperature • . . 34

3. Lipids in Wheat starch and in Its soluble and Gel Phases after Leaching at $1.5 \%$ Starch Solids . . . . . . . 35

4. Effect of Heating Rate on the Solubility and Swelling Power of wheat starch with or without Annealing . . . . . . 36

5. Comparison of the Highest Yield of Solubles (Amylose) from Wheat and corn starch at Their Optimum Solids Concentration . . 37

6. Characteristics of $\mathrm{AM}$ Isolated by Leaching and by crystallizing Its Butanol Complex . 38 


\section{LIST OF FIGURES}

\section{Figure}

Page

1. Solubility of Native Wheat and Corn

Starch and Low-Lipid Wheat starch

at Different Temperatures . . . . . 39

2. Swelling Power of Native Wheat and Corn

Starch and Low-Lipid Wheat Starch

at Different Temperatures • • • • • 41

3. Phase Diagram Showing Leaching of AM from

Wheat (3\%) at $95^{\circ} \mathrm{C}$ and a High Heating

Rate $\left(10^{\circ} \mathrm{C} / \mathrm{min}\right)$. . . . . . 43

4. Estimation of Critical Concentration $\left(\mathrm{C}_{\mathrm{O}}\right.$ at point $\mathrm{M}_{0}$ ) of Wheat Starch . . * . 45

5. Solubility of wheat starch from $0.5 \%$ to $5.4 \%$

Solids at $95^{\circ} \mathrm{C}$ and High Heating

Rate $\left(10^{\circ} \mathrm{C} / \mathrm{min}\right)$. . . . . . 47

6. Amount of AM Obtained from Leaching wheat

Starch $\left(0-5.4 \%\right.$ Solids) at $95^{\circ} \mathrm{C}$ and $\mathrm{High}$

Heating Rate $\left(10^{\circ} \mathrm{C} / \mathrm{min}\right)$. . . . 49

7. Amount of AM Leached from Wheat and corn

Starch at Various Solids Levels . . . 51

8. Amount of AM Leached from Native and Annealed

Wheat starch at $95^{\circ} \mathrm{C}$ and High Heating

Rate $\left(10^{\circ} \mathrm{C} / \mathrm{min}\right)$. . . . . . . 53

9. Amount of AM Leached from Native and Cross-

linked $\left(0.02 \% \mathrm{POCl}_{3}\right)$ Wheat starch at $95^{\circ} \mathrm{C}$ 
and High Heating Rate $\left(10^{\circ} \mathrm{C} / \mathrm{min}\right) \cdot . \quad .55$

10. High Performance Size-Exclusion (HPSE)

Chromatograms of wheat AM Leached at $75^{\circ} \mathrm{C}$

(Left Side) and of AM Isolated as Its n-Butanol

Complex (Right Side) . . . . . 57

11. HPSE Chromatograms of wheat AM Leached at $75^{\circ} \mathrm{C}$ (Left Side) and $95^{\circ} \mathrm{C}$ (Right Side) . 59

12. Size-Exclusion Chromatogram of $A M$ from

Leaching wheat Starch at $95^{\circ} \mathrm{C}$ and

$1.5 \%$ Solids . . . . . . . . . . 61

13. Size-Exclusion Chromatogram of Debranched

Gel after Leaching wheat Starch at $95^{\circ} \mathrm{C}$

and $1.5 \%$ Solids . . . . . . . . 63 


\section{Acknowledgements}

The author wishes to express his sincere appreciation to his major professor, Dr. Paul A. Seib, for his guidance and encouragement during the course of this work. He also acknowledges the valuable advice from Dr. Larry E. Erickson, and Dr. Charles W. Deyoe for serving on his advisory committee.

Thanks are extended to Dr. Sharon Lu, Dr. OKKyung Chung, and Dr. Myung Gyun shin for their assistance in this work; and to Dr. Doreen Y.T. Liang for her helpful suggstions in the laboratory.

The author is grateful to the Department of Grain Science and Industry, Kansas State University, for financial support; and to Jiangsu Agriculture College, China, for providing him with the opportunity to pursue graduate education in the United States. 
Introduction

Starch, one of the most abundant biopolymers, is the major food-reserve polysaccharide of higher plants. Normal starch is not a homopolymer, but a mixture of two glucans, amylose (AM) and amylopectin (AP). AM is predominantly a linear polymer comprised of $\alpha-1,4-1$ inked D-glucose residues, while AP has a highly ramified structure containing 95\% $\alpha-1,4$ and $5 \% \alpha-1,6-1$ inked Dglucose residues. AM molecules are smaller than those of $\mathrm{AP}$; the number-average molecular weights of $\mathrm{AM}$ and $\mathrm{AP}$ are approximately $10^{5}-10^{6}$ and $10^{8}-10^{9}$ daltons, respectively. Typically in starch, AM and AP are present in a weight ratio of approximately $1: 3$, and those molecules are arranged in a supramolecular structure in the form of a layered granule (Whistler and Daniel, $1984)$.

Starch is unique by its occurrence as tiny discrete granules with diameters between $1-100 \mu \mathrm{m}$. Starch granules in nature contain $25-40 \%$ crystalline phase as determined by x-ray diffraction (Gidley and Bociek, 1985). The remainder is amorphous. Regions of long-range ordering (crystallinity) in starch are thought to form in clusters of linear chains in the AP molecules. Furthermore, those linear chains are wound into double helices that crystallize in one of two polymorphic forms with an "A" (Imberty et al., 1988) or "B" (Imberty and 
Perez, 1988) pattern. Some native starches crystallize in a mixture of $A$ and $B$ forms; they give a "C" pattern. The amorphous phase in starch is thought to be comprised of amylose and the branched regions on the AP molecules (French, 1984; Blanshard, 1987).

The double-helical crystals in starch are insoluble in cold water, in spite of the fact that each starch molecule is highly hydroxylated and hydrophilic. Because of the amorphous phase, starch granules swell slightly in cold water (10-15\% increase in diameter). This swelling is reversible; the granules shrink back to their original dimensions on drying (Swinkels, 1984).

However, when starch granules are heated in excess water to a characteristic temperature known as the gelatinization temperature, the starch crystals in AP melt to form an elastic gel phase inside each granule. A further increase in temperature causes the double helices in the gel phase to unravel, and the granules eventually swell to many times their original size. This swelling process is largely irreversible. Meanwhile, during swelling of normal starches, amylose molecules preferentially diffuse out of the swollen granules into the continuous phase. At temperatures below $100^{\circ} \mathrm{C}$ and in the absence of high shear forces, the swollen granules (predominantly AP) in hot pastes of wheat and corn starch maintain integrity. Amylose may be collected 
in the supernatant solution after centrifugation.

Early methods of fractionating starch by aqueous leaching have been reviewed (Whistler, 1965; Banks and Greenwood, 1975; Young, 1984). However, the leaching conditions, such as heating and stirring rates, were not always clearly described by investigators. In recent years, the effects of heating and stirring rates on the solubilizing of $A M$ in hot starch pastes have been studied (Doublier, 1981; Doublier et al., 1987 a,b). Practically total solubilization of wheat amylose $(26.7 \%$ yield from starch) has been reported at $94^{\circ} \mathrm{C}, 0.5 \%$ starch solids, a low shear rate (200 rpm), and a rapid heating rate $\left(10^{\circ} \mathrm{C} / \mathrm{min}\right)$ (Doublier, 1981). Under those conditions, amylopectin remained in the gel phase. The solubilized material was thought to be pure AM because the absorbance maximum of its iodine complex ( $\lambda_{\max }$ ) was 630-640 nm.

Ghiasi et al. (1982) also studied the leaching of wheat starch $(2.7 \%$ solids $)$ at $75-95^{\circ} \mathrm{C}$ under mechanical stirring. Those authors characterized the leached material using low-pressure size-exclusion chromatography and the color of its iodide-I 2 complex. They found that small amylose molecules alone were leached at $75^{\circ} \mathrm{C}$, while at $95^{\circ} \mathrm{C}$ some amylopectin was leached together with large, more highly branched amylose. 
Leaching of amylose from starch involves three components, $\mathrm{H}_{2} \mathrm{O}, \mathrm{AM}$, and $\mathrm{AP}$, provided one ignores the low levels of minor contaminants and the polymer molecules intermediate between $\mathrm{AM}$ and $\mathrm{AP}$. Therefore, a triangular phase diagram might be used to depict the leaching process. Kalichevsky and Ring (1987) used a phase diagram to examine the incompatibility of amylose and amylopectin in aqueous solution. However, to this author's knowledge, the literature does not show a phase diagram of the aqueous leaching of amylose from starch.

The objectives of this investigation were to obtain the highest yield of AM by leaching wheat starch in water, and to compare leaching of corn and wheat starches at various conditions, including temperature, starch solids, and lipids in the starch. The effects of heating rate on the leaching process, and of annealing and cross-linking the starch prior to leaching, were also examined. Another objective was to use a triangular phase diagram to express the results of leaching of starch. Finally, the purity and structure of amylose isolated by leaching were compared to amylose isolated as its n-butanol complex. 
Materials and Methods

Materials

Prime wheat starch was obtained from Midwest Grain Products, Atchison, KS; dent corn starch was obtained from A.E. Staley Manufacturing Co., Inc., Decatur, IL. Potato starch was obtained from Sigma Chemical Company, St. Louis. MO.

B-Amylase (crystalline type I-B) was obtained from Sigma Chemical Co., (St. Louis, Mo.). One unit of the enzyme liberates $1.0 \mathrm{mg}$ of maltose from starch in $3 \mathrm{~min}$ at $\mathrm{pH} 4.8$ at $20^{\circ} \mathrm{C}$. The absence of $\alpha$-amylase and $\alpha$ glucosidase in B-amylase was checked according to the procedure of Ring et al. (1985). The commercial Bamylase (20 units) was added to $20 \mathrm{~mL}$ of $0.1 \% \mathrm{w} / \mathrm{w}$ amylose azure (amylose chemically modified with a dye, Sigma) in $0.02 \mathrm{M}$ acetate buffer at $\mathrm{pH} 5$. The mixture was placed in dialysis tubing, whose molecular weight cutoff was 6,000 . The tubing was held in a beaker of water ( 30 $\mathrm{mL})$ at $30^{\circ} \mathrm{C}$ for $24 \mathrm{~h}$, during which time no color was observed in the dialyzate. Deliberate contamination of the B-amylase preparation with 2 units of $\alpha$-amylase resulted in a detectable release of color.

The reducing power of a maltose solution ( $1 \mathrm{~mL} ; 400$ $\mu \mathrm{g} / \mathrm{mL}$ ) did not increase when incubated with the commercial B-amylase preparation ( 5 units) which inferred the absence of $\alpha$-glucosidase. 
Isoamylase (amylopectin 6-glucanohydrolase, E.C.3.2.1.68) from Pseudomonas amyloderamosa was obtained from Hayashibara Biochemical Labs Inc., okayama, Japan. The specific activity of the enzyme was about 59,000 units/mg. The enzyme (5 units) did not increase the reducing power of a maltose solution ( $1 \mathrm{~mL}$, $400 \mu \mathrm{g} / \mathrm{mL})$, which indicated no detectable $\alpha$-glucosidase in this isoamylase.

All chemicals were reagent grade.

General Methods

Protein in starch was assayed by Kjeldahl nitrogen, AACC Method 46-11; ash by dry combustion, AACC Method 08-01; moisture by oven-drying $1 \mathrm{~h}$ at $130^{\circ} \mathrm{C}$, Method 4415A (AACC, 1983). Amylograms of starches were determined according to standard procedures (Tipples, 1980) using a Brabender Viscograph-E (C.W.Brabender Instrument, Inc., Hackensack, NJ) .

Total carbohydrate was determined by the phenolsulfuric acid method (Dubois et al., 1956). Iodine binding capacity (IBC) of starch or leached carbohydrate was determined by Schoch's method (1964). The absorbance maximum $\left(\lambda_{\max }\right)$ of a polysaccharide's iodine-iodide complex was measured as described by $\mathrm{Ma}$ and Robyt (1987). Reducing power was determined by the SomoggiNelson alkaline-copper procedure (Robyt and Whelan, 1968) using maltose as standard. The degree of 
polymerization (D.P.) was calculated as follows; total carbohydrate $(\mu \mathrm{g}) /$ reducing sugar (as $\mu \mathrm{g}$ of maltose) $\times 2$. B-Amylolysis was done according to a modification (Marshall, 1974) of Whelan's procedure (1964).

Limiting viscosity number of $A M$ was determined as described by Everett and Foster (1959) after dissolving AM in dimethyl sulfoxide-water $(9: 1, v / v)$. The purity of amylose was examined by high-performance size-exclusion (HPSE) chromatography (Chuang and Syder, 1987).

Extraction of Lipids from Starch

Total lipid in starch $(10.0 \mathrm{~g})$ was estimated gravimetrically after extraction (3x) with $150 \mathrm{~mL}$ of a $3: 1(\mathrm{v} / \mathrm{v})$ mixture of $\mathrm{n}$-propanol: water at $100^{\circ} \mathrm{C}$ (Morrison and Coventry, 1985; Takahashi and Seib, 1988).

Large quantities of low-lipid starch were prepared by heating starch $(100 \mathrm{~g})$ in a boiling $\left(81^{\circ} \mathrm{C}\right)$ mixture $(3: 1, \mathrm{v} / \mathrm{v})$ of ethanol/water $(400 \mathrm{~mL})$ for $6 \mathrm{~h}$ (Takahashi and Seib, 1988). After filtration, the starch was dried in a convection oven at $40^{\circ} \mathrm{C}$ for $24 \mathrm{~h}$.

Amylose Determination and Isolation of Its n-Butanol Complex

Amylose in starch was estimated by IBC (Schoch, 1964) and by the ratio of large to small unit chains after debranching the starch molecules (Sargeant, 1982). In the latter method, starch was solubilized in dimethylsulfoxide, diluted with buffer, and debranched 
with isoamylase. The unit chains were subjected to sizeexclusion chromatography on a column of sepharose CL-2B. Since base-line resolution of the large and small unit chains was not achieved, the demarcation between large and small chains was chosen at the intermediate fraction with the lowest concentration of carbohydrate. the proportion of $\mathrm{AM}$ and $\mathrm{AP}$ was calculated using the area under the fractionation curve. Recovery of starch applied to the column was greater than $95 \%$.

Crystals of amylose-butanol complex were isolated from solubilized wheat and corn starches after three crystallizations using the method of Adkins and Greenwood (1969). Vacuum drying to constant weight gave 10-15\% AM based on starch.

Annealing of Starch Granules

An aqueous slurry of starch (15\% solids) was gently stirred at $50^{\circ} \mathrm{C}$ while microbial contamination was avoided by layering the surface with toluene (Gough and Pykus, 1971). After $72 \mathrm{~h}$, samples were either centrifuged and washed with acetone and air-dried, or were washed with water and made to suitable concentration for the amylograph. Analysis of the supernatant by phenol-sulfuric acid (Dubois et al., 1956 ) or by reaction with iodine-iodide revealed no loss of amylose during annealing.

Cross-linking of Starch 
Distarch phosphate was prepared with phosphorus oxychloride $\left(\mathrm{POCl}_{3}\right)$ in alkali containing sodium sulfate $\left(\mathrm{Na}_{2} \mathrm{SO}_{4}\right)$ ( $2 \%$ based on the dry weight of starch) (Felton and Schopmeyer, 1943; Wetzstein and Lyon, 1956; Rutenberg and Solarek, 1984). Briefly, starch (50 g d.b.) was stirred for $1-2 \mathrm{~h}$ in $70 \mathrm{~mL}$ water at $25^{\circ} \mathrm{C}$ and sodium sulfate $(1 \mathrm{~g})$ was added. The mixture was adjusted to $\mathrm{pH} 11$ by adding $1 \mathrm{M} \mathrm{NaOH}$, and $\mathrm{POCl}_{3}$ was injected slowly from a microliter syringe with continued stirring. After $30 \mathrm{~min}$ the slurry was adjusted to $\mathrm{pH} 5.5$ with $1 \mathrm{M} \mathrm{HCl,}$ and the starch collected by centrifugation. The starch was washed 3 times with water, and dried in a convection oven at $40^{\circ} \mathrm{C}$ overnight. Swelling Power and Solubility of Starch

Swelling power and solubility were determined using a modification (Kainuma et al., 1967) of the method of Leach et al. (1959). Into each of several glass centrifuge tubes $(25 \times 100 \mathrm{~mm})$ was added starch $(0.9 \mathrm{~g}$ dry solids) and water $(30 \mathrm{~mL})$. The tubes were heated in water baths at $65^{\circ} \mathrm{C}, 75^{\circ} \mathrm{C}, 85^{\circ} \mathrm{C}$, and $95^{\circ} \mathrm{C}$. During heating each slurry was gently stirred using a magnetic bar. The heating rate of the slurry was approximately $10^{\circ} \mathrm{C} / \mathrm{min}$. In some experiments done at the slow heating rate $\left(1^{\circ} \mathrm{C} / \mathrm{min}\right)$, the temperature was controlled by gradually increasing the water bath from $25^{\circ} \mathrm{C}$ to the desired temperature. Upon removal from a water bath, the 
tubes were immediately centrifuged (approximately $1000 \mathrm{x}$ $g$ for $15 \mathrm{~min})$, and the carbohydrate in the supernatant was determined. The supernatant was decanted, and the weight of the gel phase recorded. Swelling power was the ratio of the wet mass of the sedimented gel to its dry matter, and solubility was the percentage of starch dissolved in the continuous fluid phase.

In a series of leaching experiments a number of variables were examined. These included: (1) corn or wheat starch, which were either native, low-lipid, annealed or cross-linked, (2) heating rate, $1^{\circ} \mathrm{C} / \mathrm{min}$ or $10^{\circ} \mathrm{C} / \mathrm{min}$; starch solids in the slurry, 0.15 through 1.35 $\mathrm{g}$ per $30 \mathrm{~mL}$ water; and holding times of 10-60 min.

Polysaccharides in a supernatant were isolated by adding four volumes of $95 \%$ ethanol with stirring. After centrifugation, the sedimented material was washed with absolute ethanol three times and dried in a desiccator under vacuum overnight.

All leaching experiments were done in duplicate.

\section{Clarity of Supernatant}

Starches $\left(1.5 \%\right.$ solids) were leached at $75^{\circ} \mathrm{C}, 85^{\circ} \mathrm{C}$, and $95^{\circ} \mathrm{C}$ with a low stirring rate. Immediately after centrifugation, the clarity of a supernatant was determined at $650 \mathrm{~nm}$ (Craig, 1989). All the samples were adjusted with water to the same concentration of carbohydrate. 


\section{Lipid in Amylose Leached from wheat Starch}

Wheat starch $(1.5 \%)$ was leached at $85^{\circ} \mathrm{C}$ or $95^{\circ} \mathrm{C}$ at the high heating rate and low stirring rate. After centrifugation, the supernatant was freeze-dried. Alcohol was added to the gel phase with rapid stirring, the mixture evaporated to dryness under vacuum at $35^{\circ} \mathrm{C}$, and dried in a desiccator under vacuum overnight. The lipid content in each phase was quantitated by gasliquid chromatography of its fatty acid methyl ester and a multiplier factor of 1.70 (Morrison et al., 1975). Size-Exclusion Chromatography of the Gel Phase after Leaching wheat Starch

A wheat starch slurry ( $30 \mathrm{~mL}, 1.5 \%$ dry solids) was heated at $95^{\circ} \mathrm{C}$ for $30 \mathrm{~min}$. The leached solubles were decanted after centrifugation, and water was added to the gel fraction to a total volume of $20 \mathrm{~mL}$. The mixture was heated $\left(100^{\circ} \mathrm{C}\right)$ with stirring (magnetic bar) in a screw-cap pressure vial for $30 \mathrm{~min}$. An aliquot $(2 \mathrm{~mL})$ of the solution was removed immediately, and mixed with $1 \mathrm{M}$ $\mathrm{NaOH}(3 \mathrm{~mL})$. The solution was adjusted to $\mathrm{pH} 7$ with $1 \mathrm{M}$ $\mathrm{HCl}$, and sodium acetate buffer added so that the final solution $(10 \mathrm{~mL})$ had $\mathrm{pH} 3.8$ and contained $0.01 \mathrm{M}$ acetate. Isoamylase ( $15 \mu \mathrm{L}, 885$ units) was added, and the solution incubated at $35^{\circ} \mathrm{C}$ for $24 \mathrm{~h}$. After heating to boiling for $5 \mathrm{~min}$, insoluble material was removed by filtration through whatman No 1 paper. 
Debranched solution ( $5 \mathrm{~mL}$, containing approximately $10 \mathrm{mg}$ carbohydrate) was loaded onto a column (2.6 x 60 $\mathrm{cm}$ ) of Sepharose G-75 (Pharmacia Fine Chemicals, Piscatway, NJ) at room temperature, and the components eluted with water containing $0.02 \%$ sodium azide at a flow rate of approximately $10 \mathrm{~mL} / \mathrm{h}$. Fractions (approximately $6 \mathrm{~mL}$ ) were collected every $30 \mathrm{~min}$. The carbohydrate concentration in each fraction was determined by phenol-sulfuric acid, and $\lambda_{\max }$ of each fraction's iodine-iodide complex was measured. 


\section{RESULTS AND DISCUSSIONS}

The wheat and corn starches used in this study were industrial samples. However, their amylograph pasting curves were similar to those of laboratory-prepared starches (curves not shown). Other characteristics of the wheat and corn starches are listed in Table 1. The gelatinization temperatures are in excess water (Takahashi and Seib, 1988).

Amylose content in starch (Table 1) was estimated by a conventional and a relatively new method. The conventional method was based on iodine binding capacity (IBC), while the new method was based on debranching the starch molecules and separating the large and small unit chains. The large unit chains are assigned to $\mathrm{AM}$ and the small ones to AP. In our samples of corn and wheat starch, IBC estimated $3-5 \%$ more $A M$ in the starches than the debranching/molecular sizing technique (Table 1). This difference could be due to molecules in starch with a structure intermediate between $A M$ and $A P$. The IBC assay may count intermediate material as AM because with fewer branch points some of the short chains on the intermediate material would bind more $I_{2}$ than AP. Upon debranching, however, those relatively short unit chains would be counted in the AP fraction.

Effect of Temperature and Lipids on Swelling and 


\section{Solubility of Native Starch}

The solubility and swelling power of wheat and corn starches in water at $3 \%$ solids and various temperatures are shown in Figs 1 and 2, respectively. Both solubility and swelling power increased with temperature, but native starch and low-lipid starch behaved differently. It has long been hypothesized (Gray and Schoch, 1962; Krog, 1973), from the shape of pasting curves, that wheat and corn starches exhibit a two-stage swelling pattern. Internal starch lipids have been implicated in two-stage swelling. Long chain fatty acids and many of their esters, when added to starch, are well known to inhibit granule swelling, probably by forming a complex with AM after gelatinization of the granule (Leach et al., 1959; Ghiasi, 1982; Biliaderis et al., 1986; Eliasson, 1986). This may explain why the swelling power and the solubility of wheat (or corn) starch was increased by removal of its native lipids. However, at $95^{\circ} \mathrm{C}$, the swelling power of native wheat (or corn) starch was higher than its low-lipid starch (Fig. 2). This verifies that a second-stage swelling occurs at $95^{\circ} \mathrm{C}$ for native wheat and corn starches. Above $70^{\circ} \mathrm{C}$, corn starch at $3 \%$ solids had a higher swelling power than wheat starch, and both gave about the same solubility until $85^{\circ} \mathrm{C}$ (Fig. 1 \& 2). At $95^{\circ} \mathrm{C}$, however, approximately $7 \%$ more solubles was obtained from native 
and low-lipid wheat starch than from native and lowlipid corn starch.

When an aqueous slurry of native wheat starch was heated to $95^{\circ} \mathrm{C}$ and the mixture centrifuged, the supernatant phase became opaque upon cooling to $25^{\circ} \mathrm{C}$ (Table 2). However, the supernatant phase of low-lipid wheat starch remained clear. Furthermore, that opacity was not found when the slurry of native wheat starch was heated to $75^{\circ} \mathrm{C}$ and $85^{\circ} \mathrm{C}$. Those results agree with previous conclusions that at $95^{\circ} \mathrm{C}$ the lipid-AM complex in native wheat starch starts to undergo a phase change in excess water, and more lipids would be expected to leach out of the swollen granules along with amylose. Upon centrifuging and cooling the soluble phase, the AMlipid complex would re-form, and give an opaque liquid. Interestingly, the supernatant of native corn starch was clear even after leaching at $95^{\circ} \mathrm{C}$ (Table 2). It is worth noting that these clarity measurements were made immediately after centrifuging the hot starch-water mixture.

The proportion of lipid leached along with amylose from native wheat starch was determined at $1.5 \%$ starch solids and $85^{\circ} \mathrm{C}$ and $95^{\circ} \mathrm{C}$ (Table 3 ). It was found that at $85^{\circ} \mathrm{C}$, most of the lipids remained in the gel phase even though one-half the $\mathrm{AM}$ in the granule had leached into the continuous phase. At $95^{\circ} \mathrm{C}$, approximately one-half of 
the lipids in native wheat starch remained in the gel phase while almost all AM had migrated out (Table 3). It was concluded that not all lipids in wheat starch are complexed with amylose after hydration and swelling at $95^{\circ} \mathrm{C}$. This finding supports the hypothesis (Gray and Schoch, 1962; Evans, 1986) that AP may interact with certain specific long-chain amphipathic ions. However, Evans (1986) postulated that this complexing is different from $\mathrm{AM}$ complexing in that it appears to be non-cooperative in the short unit chains of AP and therefore less stable. Most of the lipid in wheat starch is lysolecithin, which is an amphipathic molecule. In contrast, only $50 \%$ of the lipid in corn starch is lysolecithin, with much of the remainder being free fatty acids (Takahashi and Seib, 1988).

\section{Phase Diagram}

Charm (1970) considers the components of a leaching system as the solvent, solute, and inert material; for the leaching of amylose from starch, those three components are water, amylose, and amylopectin, respectively. Phase diagrams are used to depict equilibrium conditions. The success in using a phase diagram to express the leaching of AM from starch granules depends on the fact that the swelling power and solubility of starch do not change with increasing leaching time under low shear forces. Doubling leaching 
time from 30 to $60 \mathrm{~min}$ at $65-95^{\circ} \mathrm{C}$ gave no change in solubility and swelling of wheat and corn starches. It is well known that the extent of gelatinization of granules does not depend on time, but on temperature.

only part of the phase triangle is shown in Fig.3 since leaching data are located in the water-rich section (upper part) of the diagram. An isosceles right triangle was preferred because for a given point on the diagram, water content can be read directly along the ordinate, and amylose concentration along the abscissa. The concentration of AP can then be calculated by difference.

The results of a leaching experiment can be conveniently documented by three points on a line in a triangular phase diagram as illustrated in Fig. 3. Point $M$ in Fig. 3 represents the initial mixture of wheat starch ( $3 \%$ solids) and water (97\%) in one leaching experiment. In all leaching experiment on wheat starch, the initial point will always lie somewhere along the line $\mathrm{H}_{2} \mathrm{O}-\mathrm{M}$ shown in Fig. 3, since $\mathrm{AM}$ in starch is fixed at 0.3 .

After heating the wheat starch slurry at $95^{\circ} \mathrm{C}$ for $30 \mathrm{~min}$ and centrifuging, the carbohydrate concentration in the supernatant was used to locate point $\mathrm{S}$ in Fig. 3, which is on the $\mathrm{H}_{2} \mathrm{O}-\mathrm{AM}$ axis because only $\mathrm{AM}$ was present in the supernatant (see discussion below). If $A M$ and $A P$ 
are co-leached out of the starch granules as in oat starch (Doubier et al., 1987b), point $S$ will be somewhere below the $\mathrm{H}_{2} \mathrm{O}-\mathrm{AM}$ axis. Point $\mathrm{G}$ in Fig. 3 was located using the following relationship; mass of supernatant/mass of wet gel = length of line MG/length of line MS.

Swelling power can be easily calculated from the phase diagram. For instance, the gel phase represented by point G in Fig. 3 contains about 5\% dry solids, i.e., the swelling power is $20 \mathrm{~g}$ wet gel/g dry solids. Solubility ( $21 \%$ of $0.9 \mathrm{~g}$ dry starch) can be calculated from the mass of the supernatant $(14 \mathrm{~g}$, from ratios of the line segments as proviously discussed), and its solids concentration (1.3\%, from the phase diagram).

Leaching data plotted on a phase diagram permits an accurate determination of the so-called critical concentration $\left(\mathrm{C}_{\mathrm{O}}\right)$ of starch, which is the concentration where the supernatant phase does not separate after heating a slurry to $95^{\circ} \mathrm{C}$ and centrifuging (Leach, 1965). In other words, when the starch concentration is above the critical value, the swollen granules form a continuous phase in which all available water is entrained. In the past, $C_{o}$ of a starch was estimated (Leach, 1965) by the reciprocal of the swelling power of starch when heated in water to $95^{\circ} \mathrm{C}$ at a low solids 
level. That estimate is correct only if the starch has the same swelling power at all concentrations below its critical concentration. However, an increase in starch concentration eventually leads to macromolecular entanglement, which decreases swelling power as starch concentration increases. Thus, the reciprocal of swelling power underestimates the critical concentration.

Determination of the critical concentration of wheat starch using the phase diagram is shown in Fig. 4. Increasing levels of wheat starch decrease the volume of the supernatant as shown by the decreasing lengths of line segments $\mathrm{M}_{3} \mathrm{G}_{3}, \mathrm{M}_{2} \mathrm{G}_{2}$, and $\mathrm{M}_{1} \mathrm{G}_{1}$ (Fig. 4). The critical concentration $\left(M_{O}\right)$ of wheat starch in Fig. 4 was estimated to be $5.4 \%$. If the critical concentration is calculated from the reciprocal of the swelling power of wheat starch $(24.8 \mathrm{~g}$ water $/ \mathrm{g}$ dry starch) found in this work at $1.5 \%$ starch solids, a value of $4.2 \%$ is calculated. Previously, Leach (1965) reported the critical concentration for wheat starch to be $5.0 \%$.

It is important to notice that for leaching AM from starch, points $G, M$, and $S$ lie on a straight line. However, the line does not pass though the origin of the phase diagram. This result means that the concentration of $A M\left(g / \mathrm{mL} \mathrm{H}_{2} \mathrm{O}\right)$ in the supernatant water is greater than its concentration $\left(\mathrm{g} / \mathrm{mL} \mathrm{H}_{2} \mathrm{O}\right)$ in the gel phase 
water. This suggests that most of the water in the gel phase interacts with AP in the gel phase to lower its fugacity.

Starch Level in Slurry; Effect on Yield of Solubles During Leaching

As we have shown in the phase diagram (Fig.4), the volume of supernatant decreases with increasing starch solids concentration. For that reason, the yield of solubles ( $g$ of solubles/100 g dry solids), which is practically pure AM, decreases with increasing starch concentration at $>1.5 \%$ solids (Fig. 5). When wheat starch concentrations were below $1.5 \%$, almost $29 \%$ of the starch was obtained in the supernatant phase. Obviously, the quantity of $A M$ obtained from starch subjected to leaching is the product of the yield of solubles ( $g / 100$ g starch) and the starch solids concentration ( $g$ starch/100 $\mathrm{mL} \mathrm{H}_{2} \mathrm{O}$ ). Fig. 6 shows the quantity of $\mathrm{AM}$ obtained from wheat starch at $95^{\circ} \mathrm{C}$ and a fast heating rate. The highest yield of $\mathrm{AM}$ was obtained at $3 \%$ solids. Absolute yields, of course, will double if one doubles the volume of a batch of starch slurry at $3 \%$ solids as shown in Fig. 6 .

A comparison of the AM yields from wheat and corn starch at various solids levels is shown in Fig. 7. At concentrations below $1.5 \%$ starch solids, AM yield was almost the same from wheat vs corn. However, at $3.0 \%$ 
starch solids, about $40 \%$ more soluble AM was obtained from wheat than corn starch.

Effect of Annealing, Heating Rate, and Cross-linking

It is well known that warm water soaking of starch granules below its gelatinization temperature anneals or perfects the crystallites in the granules. Annealing decreased the swelling power and the solubility of potato starch (Kuge and Kitamura, 1985), while its gelatinization temperature and temperature range increased along with the enthalpy of the gelatinization (Gough and Pybus, 1971; Marchant and Blanshard, 1978; Kuge and Kitamura, 1985; Krueger et al., 1987).

Fig. 8 shows that annealed native wheat starch swelled less than native starch, but it was more soluble at $95^{\circ} \mathrm{C}$ and $3 \%$ starch solids. Indeed, $40 \%$ more AM was obtained from annealed wheat starch in a $3.0 \%$ slurry at $95^{\circ} \mathrm{C}$ and the fast heating rate. Annealed low-lipid wheat starch, however, gave both lower solubility and swelling power than low-lipid starch (Table 4). This suggests that the internal structure of the low-lipid granule was modified during annealing.

The benefit of annealing wheat starch prior to its leaching at the fast heating rate may be explained by two effects. The double helices of the linear chains in the AP molecules may become more perfect, which would help stabilize the gel phase on the swollen granules. At 
the same time, lipids may complex with AM during annealing and facilitate release of $\mathrm{AM}$ from the swollen granules.

Corn starch, when annealed, behaved similar to wheat starch. The highest yield of AM from wheat and corn starches at their optimum solids concentration are compared in Table 5 . The highest quantity $(0.8 \mathrm{~g}, 22 \%$ yield based on starch) of $\mathrm{AM}(30 \mathrm{~mL}$, total volume) was from annealed wheat starch, whereas $0.7 \mathrm{~g}$ (23\% yield) was obtained from annealed corn starch.

slow heating of native corn or wheat starch slurries during leaching gave the same benefit as did pre-annealing of starch follow by leaching at a high heating rate $\left(10^{\circ} \mathrm{C} / \mathrm{min}\right)$. Slow heating gave in situ annealing as evidenced by the decrease in swelling power $\left(95^{\circ} \mathrm{C}\right)$ of wheat starch from $23 \mathrm{~g} / \mathrm{g}$ at $10^{\circ} \mathrm{C} / \mathrm{min}$ to $13 \mathrm{~g} / \mathrm{g}$ at a slow heating rate (Table 4 ). At the same time, the solubility slightly increased from 21 to $23 \%$. Therefore, one can increase the starch solids during leaching if a slow heating rate $\left(1^{\circ} \mathrm{C} / \mathrm{min}\right)$ is used simply because more supernatant is obtained.

once again, wheat starch lipids played an important role during leaching at the slow heating rate. When lipids were present, slow-heating $\left(1^{\circ} \mathrm{C} / \mathrm{min}\right)$ or $\underline{\text { in }}$ situ annealing gave lower swelling power but slightly higher solubility than at the high heating rate (Table 5). 
However, if lipids were removed, both swelling power and solubility were reduced at the solw-heating rate. The same effects were true for corn starch.

When wheat starch was cross-linked $\left(0.02 \% \mathrm{POCl}_{3}\right)$, the AM obtained at $95^{\circ} \mathrm{C}$, and a high heating rate $\left(10^{\circ} \mathrm{C} / \mathrm{min}\right)$ had higher B-amylolysis ( $87 \%$ vs $80 \%$ ) compared to AM from native wheat starch. However, the quantity of AM was not improved (Fig. 9) probably because crosslinking tied up $A M$ molecules in the granules as well. In support of that hypothesis, we found that much less amylose ( $3.6 \%$ based on starch) was leached from crosslinked potato starch than from similarly cross-linked wheat starch $(20.7 \%$ based on starch). Amylose molecules in potato starch are approximately four times larger than those in wheat starch (Hizukuri, 1988), and the probability of attaching AM to the AP molecules is proportional to molecular size.

AM Obtained by Leaching compared to AM Isolated by crystallizing Its n-Butanol Complex

Some characteristics of leached AM were compared to AM isolated as its n-butanol complex (Table 6). The results were generally in agreement with the previous study by Ghiasi et al. (1982). Iodine binding capacities for leached AM were high, and decreased slightly as the leaching temperature was increased (Table 6). Meanwhile, AM yield, degree of polymerization $\left(D P_{n}\right)$ and intrinsic 
viscosity increased with increasing temperature of leaching, while $B$-amylolysis decreased and $\lambda_{\max }$ remained about the same.

AM molecules isolated by leaching were larger than those crystallized as its butanol complex (compare elution times in Fig.10). Those two methods of isolating AM involve different mechanisms. Isolation of AM by leaching is strongly dependent on the structure of the starch granule and the distribution of $A M$ inside the granules. On the other hand, AM crystallized with nbutanol depends on the growth of a crystalline phase in the presence of dissolved AP and intermediate material.

HPSE curves (Fig. 10) showed a more uniform but broader distribution of leached AM molecules at $75^{\circ} \mathrm{C}$ compared to a thrice-crystallized sample of AM-n-butanol complex. The HPSE curve (Fig. 11) for AM leached at $95^{\circ} \mathrm{C}$ suggests contamination of the AM with some higher molecular component having a different structure.

Further investigation of the purity of leached AM at $95^{\circ} \mathrm{C}$ was done using low-pressure size-exclusion chromatography (Fig. 12). Wheat starch (1.5\% starch solids) was leached at $95^{\circ} \mathrm{C}$ and a high heating rate (10 $\left.{ }^{\circ} \mathrm{C} / \mathrm{min}\right)$, and the solubilized material was separated on Sepharose CL-2B. Fig.12 shows the presence of a minor component ( $4 \%$ ) having a larger molecular size than the major component ( $96 \%, \mathrm{AM})$. Subfractions were examined 
for the color of their $I_{2}$-complex. The largest molecules in the minor fraction showed $\lambda_{\max } 580 \mathrm{~nm}$, which gradually shifted to $\lambda_{\max } 630 \mathrm{~nm}$ for its smallest molecules. This suggest that small amounts of AP or branched, large AM molecules were leached out at $95^{\circ} \mathrm{C}$ along with practically all AM.

The gel phase remaining after leaching AM from wheat starch at $95^{\circ} \mathrm{C}$ was debranched to give a mixture of the unit chains. A size-exclusion chromatogram of the unit chains on Sepharose G-75 is shown in Fig. 13. $\lambda_{\max }$ of each fraction's $I_{2}$-complex was $560-580 \mathrm{~nm}$ except that of the first peak (about 2-3\% of total carbohydrates), which gave $\lambda_{\max }$ of $620 \mathrm{~nm}$. The low level of AM-type molecules in the gel phase confirmed that almost all AM had been solubilized in the continuous phase.

Future Work

Possible uses of wheat $A M$ and $A P$ will be explored in food systems. 


\section{Reference}

Adkins, G. K., and Greenwood, C. T. 1969. Studies on starches of higher amylose content. Part $x$. An improved method for the fractionation of maize and amylomaize starches by complex formation from aqueous dispersion after pretreatment with methyl sulfoxide. Carbohydr. Res. 11:217.

American Association of Cereal Chemists. 1983. Approved Methods of the AACC. Methods $08-01$ and 44-15A, revised October 1981; Method 46-11, revised October 1982. The Association, St. Paul, MN.

Banks, W., and Greenwood, C. T. 1975. Starch and its Components. University Press, Edinburgh.

Biliaderis, C. G., Page, C. M., and Maurice, T. J. 1986. on the multiple melting transitions of starch/monoglyceride systems. Food Chem. 22:179. Blanshard, J. M. V. 1987. Starch granule structure and function: a physicochemical approach. in: starch: Properties and Potential. Galliard, T., ed. John Wiley \& Sons, New York.

Charm, S. E. 1970. Extraction. in: The Fundamentals of Food Engineering. 2nd ed. Charm, S. E., ed. AVI Publishing Co., Inc., Westport, CT. Chuang, J.-Y., and Sydor, R. J. 1987. High performance size exclusion chromatography of starch with dimethyl sulfoxide as the mobile phase. J. Appl. Polymer Sci. 
$34: 1739$.

Craig, S. A. S., Maningt, C. C., Seib, P. A. and

Hoseney, R. C. 1989. Starch Paste Clarity. Cereal Chem. in press.

Doublier, J. L. 1981. Rheological studies on starch-

flow behaviour of wheat starch pastes. Starch, $33: 415$.

Doublier, J. L., Llamas, G., and Meur, M. L. 1987a. A rheological investigation of cereal starch pastes and gels. Effect of pasting procedures. Carbohydr. Polymer $7: 251$.

Doublier, J. L., Paton, D., and Llamas, G. 1987b. A rheological investigation of oat starch pastes. Cereal Chem. 64:21.

Dubois, M., Gilles, K. A., Hamilton, J. K., Reber, P. A., and Smith, F. 1956. Colorimetric method for determination of sugars and related substance. Anal. Chem. $28: 350$.

Eliasson, A.-C. 1986. On the effects of surface active agents of the gelatinization of starch--a calorimetric investigation. Carbohydr. Polymer $6: 463$.

Everett, W. W., and Foster, J. 1959. The comformation of amylose in solution. J. Am. Chem. Soc. 81:3459. Evans, I. D. 1986. An investigation of starch/surfactant interaction using viscosimetry and 
differential scanning calorimetry. Starch 38:227.

Felton, G. E., and Schopmeyer, H. H. 1943. Thick-bodied starch and method of making. U. S. Patent 2,328,537; chem. Abstr. 38:889 (1944).

French, D. 1984. Organization of starch granules. in:

Starch Chemistry and Technology. Whistler, R. L., BeMiller, J. N., and Paschall, E. F., eds. Academic Press, New York.

Gidley, M. J., and Bociek, S. M. 1985. Molecular organization in starches: $A{ }^{13} \mathrm{C}$ CP/MAS NMR study. J. Am. Chem. Soc. 107:7040.

Gough, B. M., and Pybus, J. N. 1971. Effect on the gelatinization temperature of wheat starch granules of prolonged treatment with water at $50^{\circ} \mathrm{C}$. Staerke $23: 210$.

Gray, V. M., and Schoch, T. J. 1962. Effects of surfactants and fatty adjuncts on the swelling and solubilization of granular starches. Staerke $14(3): 239$.

Hizukuri, S. 1988. Recent advances in molecular structures of starch. J. Jpn. Soc. Starch Sci. $35: 185$.

Imberty, A., Chanzy, H., Perez, S., Buleon, A., and Tran, V. 1988. The double-helical nature of the crystalline part of A-starch. J. Mol. Biol. 201:365. Imberty, A., and Perez, S. 1988. A revisit to the 
three-dimensional structure of B-type starch. Bioplymers 27:1205.

Kainuma, K., Oda, T., and Suzuki, S. 1967. Studies on the phosphate derivatives of starch. Part I. Synthesis of phosphorous cross linked starch with aqueous solution of phosphrous pentaoxided. J. Tech. Soc., $14(1): 24$.

Kalichevsky, M. T., and Ring, S. G. 1987.

Incompatibility of amylose and amylopectin in aqueous solution. Carbohydr. Res. 162:323.

Krog, N. 1973. Influence of food emulsifiers on pasting temperature and viscosity of various starches. Staerke 25:22.

Krueger, B. R., Knutson, C. A., Inglett, G. E., and Walker, C. E. 1987. A differential scanning calorimetry study on the effect of annealing on gelatinization behavior of corn starch. J. Food Sci. $52(3): 715$.

Kuge, T., and Kitamura, S. 1985. Annealing of starch granules--warm water treatment and heat-moisture treatment. J. Jpn. Soc. Starch Sci. 32(1):65.

Kugimiya, M., Donovan, J. W., and Wong, R. Y. 1986. Phase transitions of amylose-lipid complexes in starch: a calorimetric study. Starch 32:265. Leach, H. W., McCowen, L. D., and Schoch, T. J. 1959. Structure of the starch granule. I. Swelling and 
solubility patterns of various starches. Cereal Chem. $36: 534$.

Ma, W. P., and Robyt, J. F. 1987. Preparation and characterization of soluble starches having different molecular size and composition, by acid hydrolysis in different alcohols. Carbohydr. Res. $166: 283$.

Marchant, J. L., and Blanshard, J. M. V. 1978. Studies of the dynamics of the gelatinization of starch granules employing a small angle light scattering system. Staerke 30:257.

Marshall, J. J. 1974. Application of enzymic methods to the structural analysis of polysaccharides: Part I. Adv. Carbohydr. Chem. Biochem. 30:257.

Morrison, W. R., Mann, D. L., Soon, W., and Coventry, A. M. 1975. Selective extraction and quantitative analysis of non-starch and starch lipids from wheat flour. J. Sci. Fd Agric. 26:507.

Ring, S. G., I'Anson, K. J., and Morris, V. J. 1985. Static and dynamic light scattering studies of amylose solutions. Macromolecules 18:182. Robyt, J. F., and Whelan, W. J. 1968. Amylases and their action on starch. in: starch and Its Derivatives. Radley, J. A., ed. Chapman and Hall, London.

Rutenberg, M. W. , and Solarek, D. 1984. Starch 
derivatives: production and uses. in: Starch Chemistry and Technology, 2nd ed. Whistler, R. L., BeMiller, J. N., and Paschall, E. F., eds. Academic Press, Orlands, FL.

Sargeant, J. G. 1982. Determinations of amylose: amylopectin ratios of starches. Starch 34:89. Schoch, T. J. 1964. Iodimetric determination of amylose. Potentiometric titration: Standard methods. Methods Carbohydr. Chem. IV:157. Swinkels, J. J. M. 1984. Sources of starch, its chemistry and physics. in: Starch Conversion Technology. Van Beynum, G. M. A. and Roels, J. A., eds. Marcel Dekker, Inc., New York.

Takahashi, S. and Seib, P. A. 1988. Paste and gel properties of prime corn and wheat starches with and without native lipids. Cereal Chem. 65(6):474. Tipples, K. H. 1980. Use and applications. in: The Amylograph Handbook. Am. Assoc. Cereal Chem., St. Paul, MN.

Wetzstein, H. W., and Lyon, P. 1956. Manufacture of modified starches. U. S. Patent 2,754.232. Chem. Abstr. 50:13490 (1956).

Whelan, W. J. 1964. Hydrolysis with B-amylase and preparation of the B-amylase limit dextrin of amylopectin. Methods Carbohydr. Chem. IV:261. Whistler, R. L. 1965. Fractionation of Starch. in: 
Starch Chemistry and Technology. Vol. I. Whistler, R. L. and Paschall, E. F., eds. Academic Press, New York.

Whistler, R. L. and Daniel, J. R. 1984. Molecular structure of starch. in: Starch Chemistry and Technology. Whistler, R. L., BeMiller, J. N. and Paschall, E. F., eds. Academic Press, New York. 
Table 1. Some Characteristics of Wheat and corn Starch

\begin{tabular}{lcc}
\hline & Wheat & Corn \\
\hline Moisture, \% & 10.1 & 10.3 \\
Lipid, $\%$ & 1.0 & 0.9 \\
Nitrogen, \% & 0.08 & 0.1 \\
Gelatinization & & \\
temperature, ${ }^{\circ}$ & $48-73$ & $58-79$ \\
Amylose, $\%$ & $30.2^{\mathrm{a}}$ & $29.5^{\mathrm{a}}$ \\
& $27.0^{\mathrm{b}}$ & $25.0^{\mathrm{b}}$ \\
\hline
\end{tabular}

$\mathrm{a}_{\text {Based on }}$ iodine binding capacity.

based on debranching/size exclusion method. 
Table 2. Clarity of Supernatant after Leaching Starch (1.5\%) at Different Temperatures

\begin{tabular}{llll}
\hline & \multicolumn{3}{c}{$\%$ T, 650 nm } \\
\cline { 3 - 4 } Temperature $\left({ }^{\circ} \mathrm{C}\right)$ & $\underline{75}$ & $\underline{85}$ & $\underline{95}$ \\
\hline Wheat Starch & & & \\
Native & 99.1 & 98.2 & 69.8 \\
Low-lipid & 99.2 & 99.0 & 94.1 \\
Corn Starch & 98.6 & 97.8 & 96.2 \\
Native & 98.9 & 98.1 & 97.7 \\
Low-lipid & & & \\
\hline
\end{tabular}


Table 3. Lipids in wheat starch and in Its Soluble and Gel Phases after Leaching at $1.5 \%$ Starch Solids

\begin{tabular}{lrr} 
Temperature $\left({ }^{\circ} \mathrm{C}\right)$ & 85 & 95 \\
\hline Swelling Power, g/g & 13.0 & 24.8 \\
Solubility, $\%$ & 16.2 & 29.0 \\
Total Lipida mg & 9.6 & 9.6 \\
Lipid in Soluble Phaseb, mg & 1.5 & 3.6 \\
Lipid in Gel Phasec, mg & 7.0 & 3.7
\end{tabular}

$\mathrm{a}_{\text {Based on } 1}$ gram of dry starch.

b Soluble phase from $1 \mathrm{~g}$ of dry starch was $0.16 \mathrm{~g}$ at $85^{\circ} \mathrm{C}$, and $0.29^{\mathrm{g}}$ at $95^{\circ} \mathrm{C}$.

$\mathrm{C}_{\mathrm{Gel}}$ phase from $1 \mathrm{~g}$ of dry starch was $0.84 \mathrm{~g}$ at $85^{\circ} \mathrm{C}$, and $0.71 \mathrm{~g}$ at $95^{\circ} \mathrm{C}$. 
Table 4. Effect of Heating Rate on the Solubility and Swelling power of wheat Starch with or without Annealing ${ }^{a}$

\begin{tabular}{|c|c|c|c|c|c|}
\hline \multirow{2}{*}{$\begin{array}{l}\text { Heating } \\
\text { Rate, } \\
10^{\circ} \mathrm{C} / \mathrm{min}\end{array}$} & $\begin{array}{l}\text { Wheat } \\
\text { starch }\end{array}$ & \multicolumn{2}{|c|}{ Solubility, $\%$} & \multicolumn{2}{|c|}{ Swelling Power, $\mathrm{g} / \mathrm{g}$} \\
\hline & & & & & \\
\hline & Control & 20.6 & 23.3 & 23.0 & 19.7 \\
\hline & Annealed & 24.4 & 13.8 & 14.6 & 14.0 \\
\hline & Control & 23.4 & 22.4 & 13.0 & 12.1 \\
\hline & Annealed & 22.4 & 12.7 & 12.2 & 11.6 \\
\hline
\end{tabular}

at $95^{\circ} \mathrm{C}$ and $3.0 \%$ wheat starch solids. 
Table 5. Comparison of the Highest Yield of Solubles

(Amylose) from Wheat and Corn Starch at Their optimum Solids Concentration ${ }^{2}$.

\begin{tabular}{|c|c|c|c|c|}
\hline & & $\begin{array}{l}\text { Optimum } \\
\text { solids, } \%\end{array}$ & AM $\underset{\%}{\text { Yield }}$ & $\begin{array}{l}\text { Quantity } \\
\text { of } \mathrm{AM}^{\mathrm{C}}, \mathrm{g}\end{array}$ \\
\hline \multirow[t]{3}{*}{ Wheat } & Starch & & & \\
\hline & Native & 3.0 & 21 & 0.63 \\
\hline & Annealed & 3.5 & 22 & 0.77 \\
\hline \multirow[t]{3}{*}{ Corn } & Starch & & & \\
\hline & Native & 2.3 & 18 & 0.41 \\
\hline & Annealed & 3.0 & 23 & 0.69 \\
\hline
\end{tabular}

at $95^{\circ} \mathrm{C}$ using high heating rate $\left(10^{\circ} \mathrm{C} / \mathrm{min}\right)$ and slow stirring.

b Based on starch.

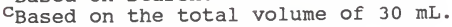


Table 6. Characteristics of AM Isolated by Leaching and by Crystallizing Its Butanol Complex

\begin{tabular}{|c|c|c|c|c|}
\hline & \multicolumn{3}{|c|}{ Leaching Temperature, ${ }^{\circ} \mathrm{C}$} & \multirow{2}{*}{$\begin{array}{c}\mathrm{BuOH} \\
\text { Crystallization }\end{array}$} \\
\hline & $\underline{75}$ & 85 & 95 & \\
\hline Yield, \% & 13.6 & 18.8 & 23.3 & - \\
\hline IBC, $\%$ & 19.1 & - & 17.6 & 19.3 \\
\hline $\mathrm{DPn}$ & 827 & 875 & 1204 & 720 \\
\hline$[\eta], \mathrm{mL} / \mathrm{g}$ & 203 & 252 & 278 & 128 \\
\hline B-amylolysis & 93.0 & 83.4 & 80.3 & 81.7 \\
\hline$\lambda_{\max }, \mathrm{nm}$ & 640 & 635 & 635 & 640 \\
\hline
\end{tabular}


Fig. 1. Solubility of native wheat and corn starch and low-lipid wheat starch at different temperatures. 


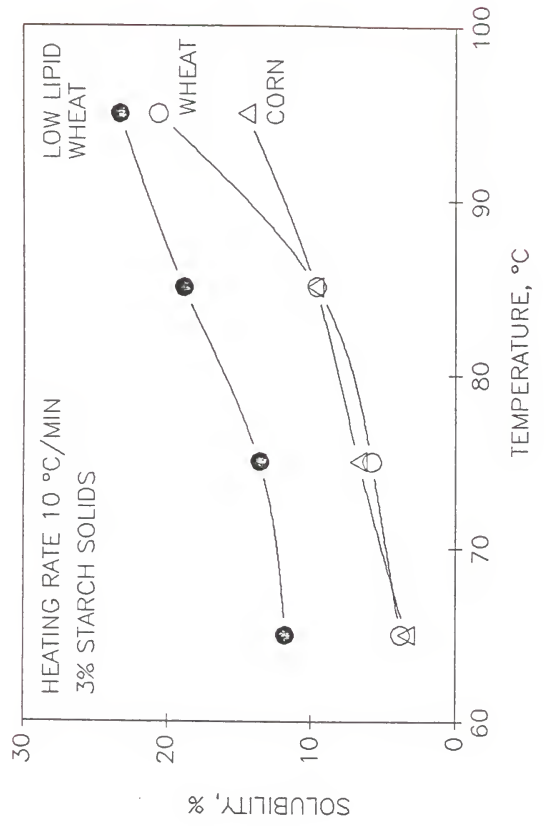


Fig. 2. Swelling power of native wheat and corn starch and low-lipid wheat starch at different temperatures. 


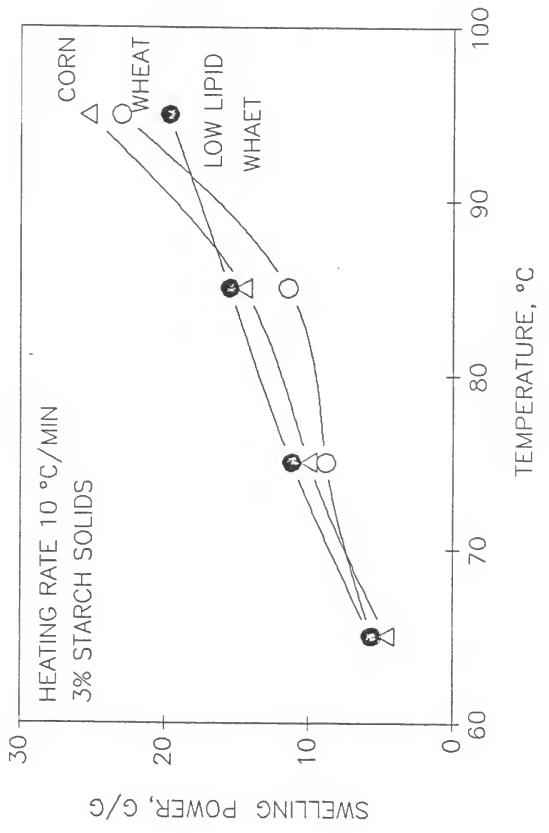


Fig. 3. Phase diagram showing leaching of AM from wheat starch (3\%) at $95^{\circ} \mathrm{C}$ and a high heating rate $\left(10^{\circ} \mathrm{C} / \mathrm{min}\right)$. 


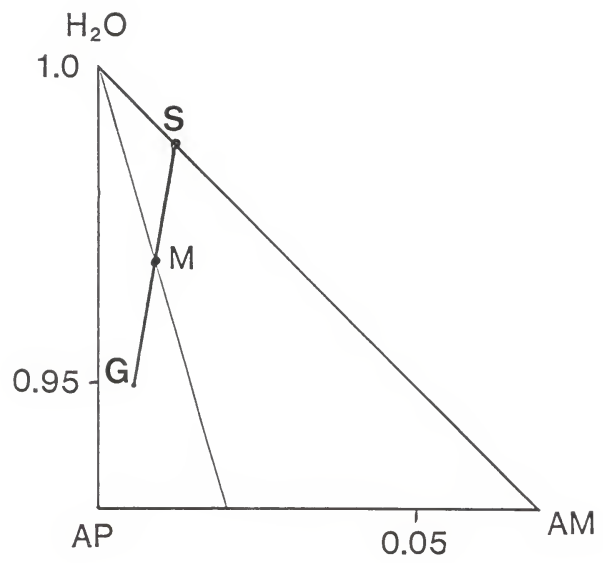


Fig. 4. Estimation of critical concentration ( $C_{0}$ at point $\mathrm{M}_{\mathrm{O}}$ ) of wheat starch. 


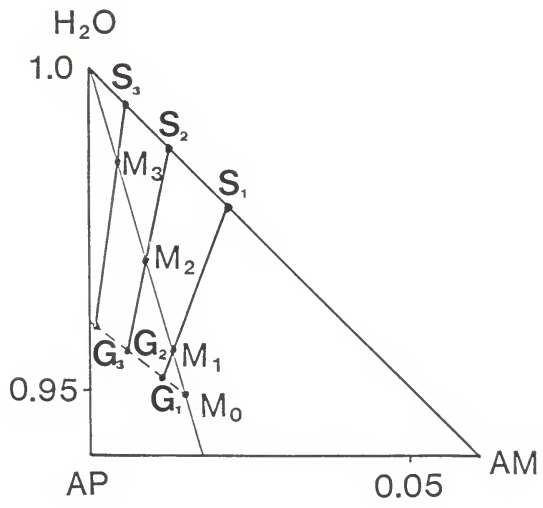


Fig. 5. Solubility of wheat starch from $0.5 \%$ to $5.4 \%$ solids at $95^{\circ} \mathrm{C}$ and high heating rate $\left(10^{\circ} \mathrm{C} / \mathrm{min}\right)$. 


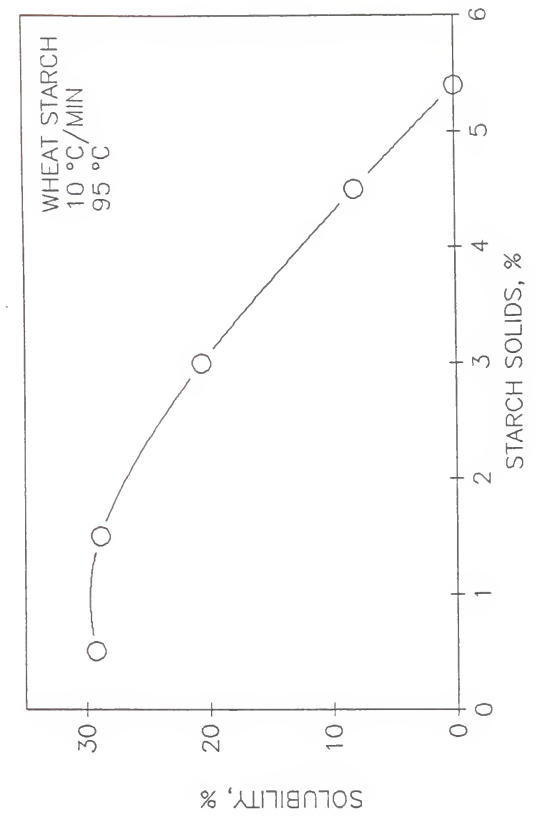


Fig. 6. Amount of AM obtained from leaching wheat starch $\left(0-5.4 \%\right.$ solids) at $95^{\circ} \mathrm{C}$ and high heating rate $\left(10^{\circ} \mathrm{C} / \mathrm{min}\right)$. 


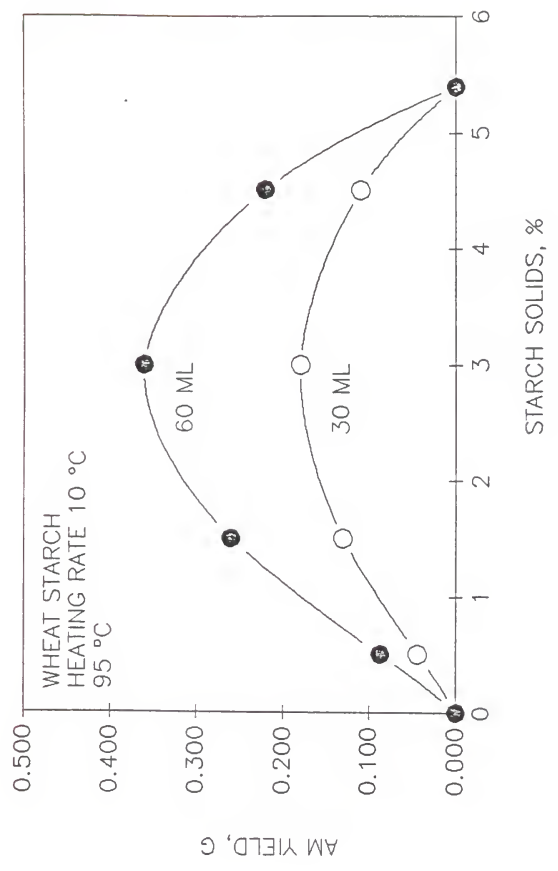


Fig. 7. Amount of AM leached from wheat and corn starch at various solids levels. 


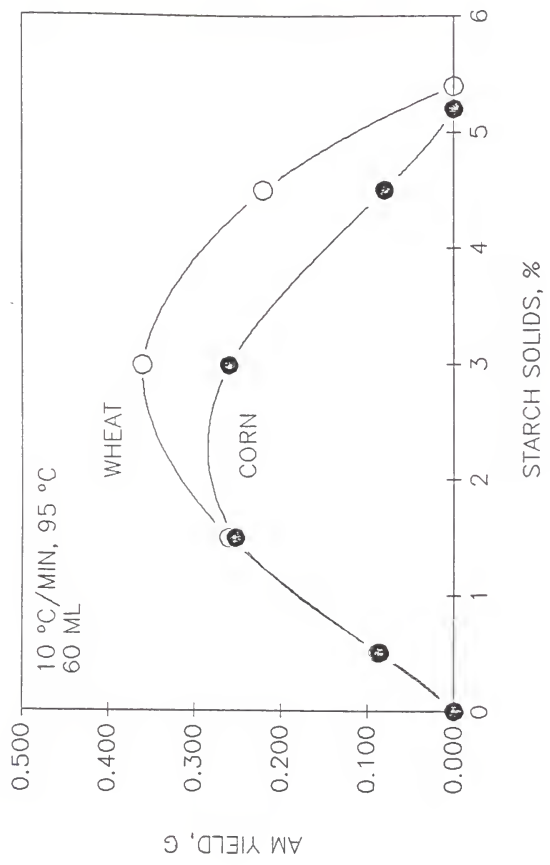


Fig. 8. Amount of $A M$ leached from native and annealed wheat starch at $95^{\circ} \mathrm{C}$ and high heating rate $\left(10^{\circ} \mathrm{C} / \mathrm{min}\right)$. 


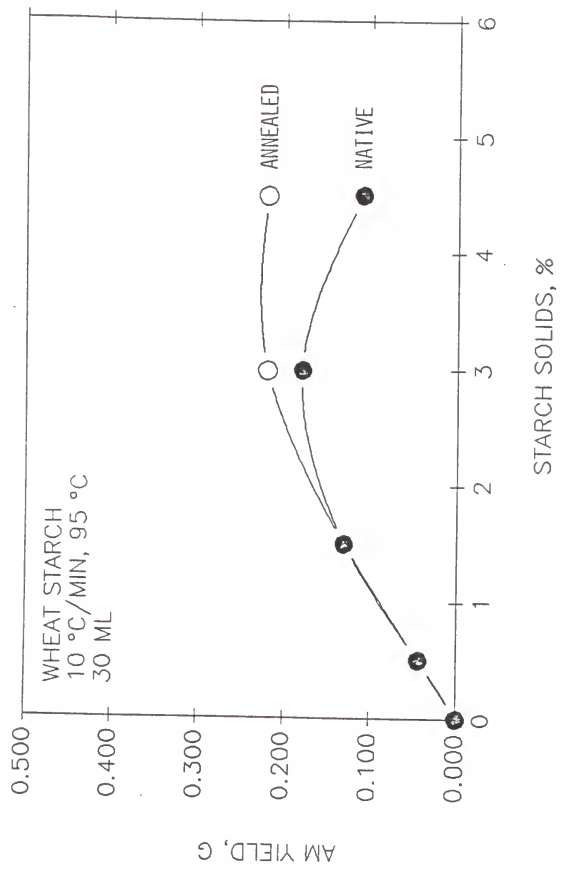


Fig. 9. Amount of AM leached from native and crosslinked $\left(0.02 \% \mathrm{POCl}_{3}\right)$ wheat starch at $95^{\circ} \mathrm{C}$ and high heating rate $\left(10^{\circ} \mathrm{C} / \mathrm{min}\right)$. 


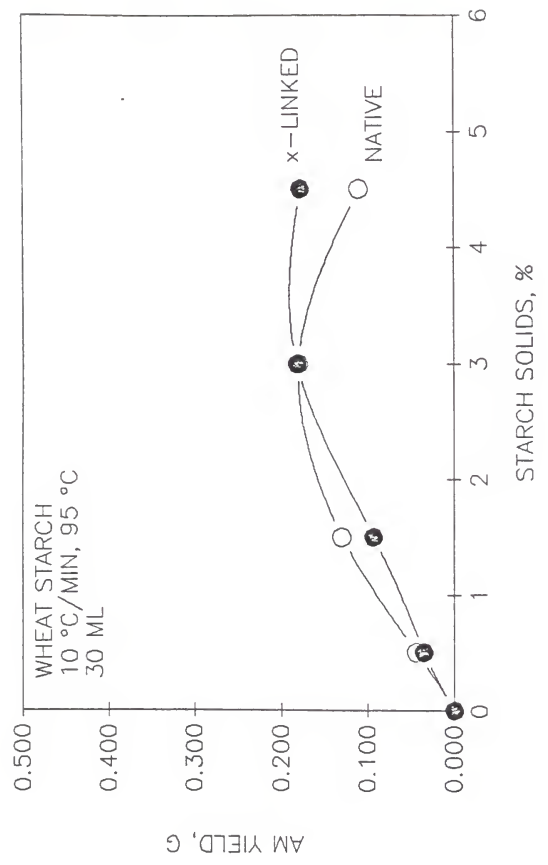


Fig. 10. High performance size-exclusion (HPSE)

chromatograms of wheat $\mathrm{AM}$ leached at $75^{\circ} \mathrm{C}$ (left side) and of AM isolated as its n-butanol complex (right side). 


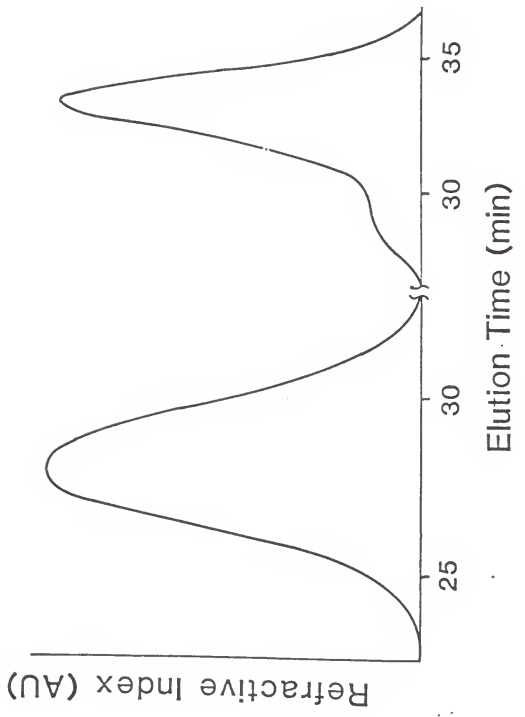


Fig. 11. HPSE chromatograms of wheat AM leached at $75^{\circ} \mathrm{C}$ (left side) and $95^{\circ} \mathrm{C}$ (right side). 


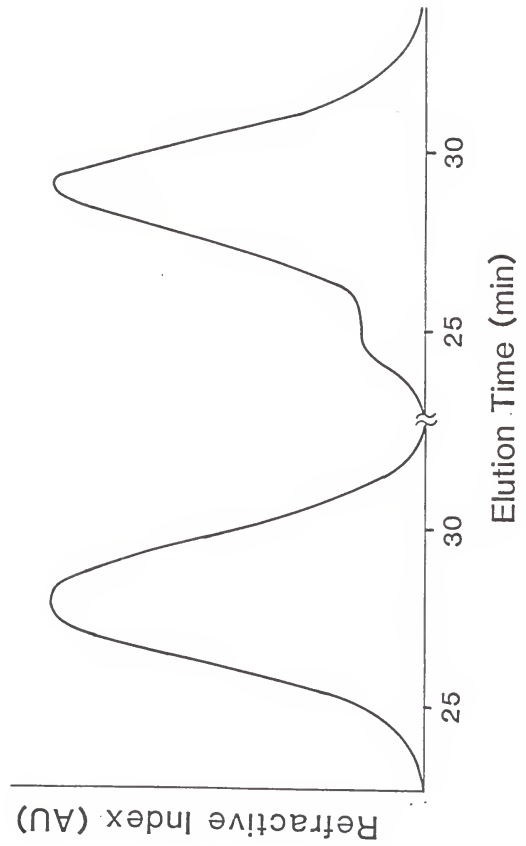


Fig. 12. Size-exclusion chromatogram of AM from leaching wheat starch at $95^{\circ} \mathrm{C}$ and $1.5 \%$ solids. 


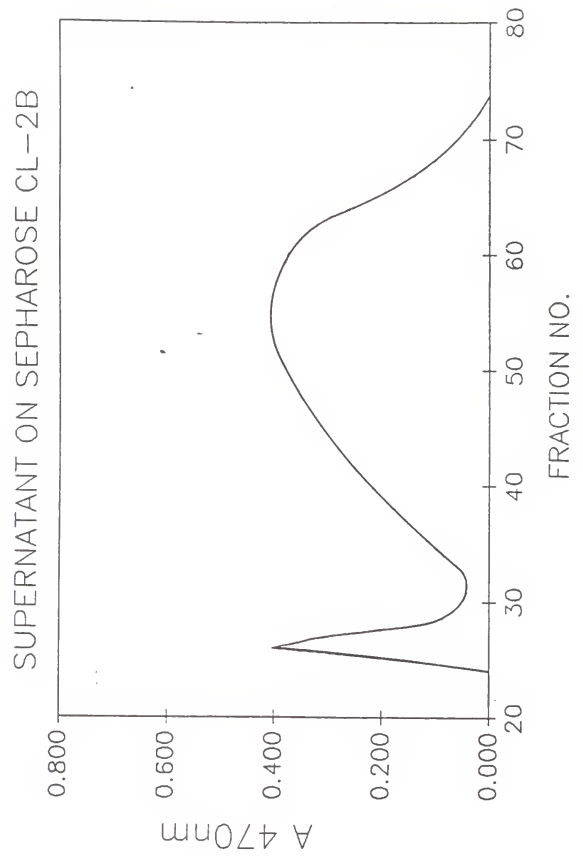


Fig. 13. Size-exclusion chromatogram of debranched gel phase after leaching wheat starch at $95^{\circ} \mathrm{C}$ and $1.5 \%$ solids. 


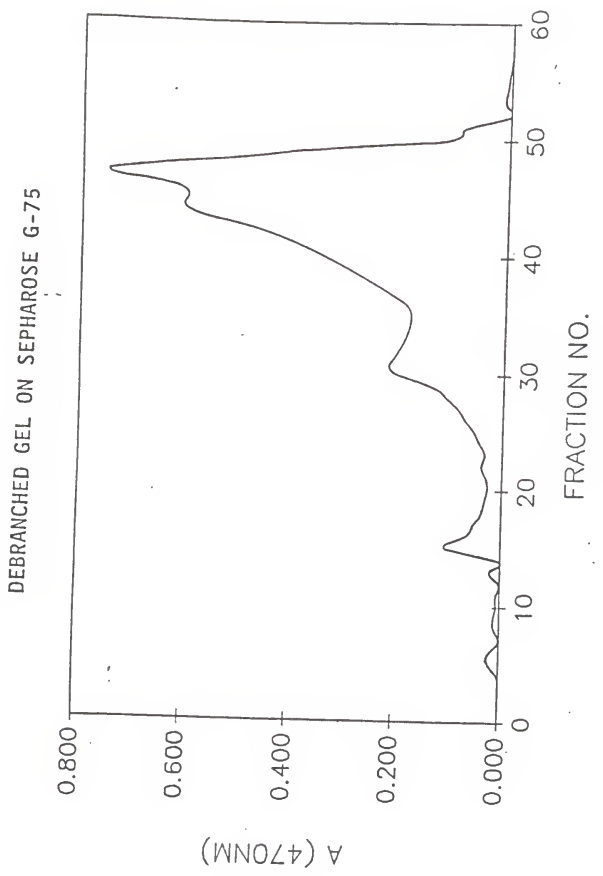


LEACHING OF AMYLOSE FROM WHEAT AND CORN STARCH

$$
\text { by }
$$

YONGCHENG SHI

B.S., Zhejiang University, China, 1984

AN ABSTRACT OF A THESIS

Submitted in partial fulfillment of the

requirements for the degree

MASTER OF SCIENCE

Department of Grain Science and Industry

KANSAS STATE UNIVERSITY

Manhattan, Kansas 
ABSTRACT

The highest yield (21\% based on starch) of amylose (AM) was obtained from wheat starch by leaching at $3 \%$ solids and $95^{\circ} \mathrm{C}$ under mild agitation and at a high heating rate $\left(10^{\circ} \mathrm{C} / \mathrm{min}\right)$. Annealing wheat starch prior to leaching at $95^{\circ} \mathrm{C}$ or using a slow heating rate (1 ${ }^{\circ} \mathrm{C} / \mathrm{min}$ ) during leaching increased $\mathrm{AM}$ yield from $21 \%$ to $23 \%$ at $3.0 \%$ starch solids, and $8 \%$ to $16 \%$ at $4.5 \%$ starch solids. At $0.5 \%$ solids, almost all wheat AM $(29 \%$ of starch) was solubilized into the continuous phase at $95^{\circ} \mathrm{C}$, but only one-half of lipid in the starch coleached with AM. Corn starch during leaching behaved similarly to wheat starch below $1.5 \%$ starch solids, while at $3.0 \%$, almost $40 \%$ more $A M$ was obtained from wheat starch. Wheat AM molecules isolated by leaching were larger than those obtained by crystallizing its nbutanol complex, and they gave a different sizedistribution as evidenced by high-performance sizeexclusion chromatography. A triangular phase diagram was found useful to depict the overall process of leaching of starch. The critical concentrations of wheat (5.4\%) and corn (5.2\%) starches were determined from phase diagrams. 